\title{
REPRESENTAÇÕES SOCIAIS SOBRE REDUÇÃO DA MAIORIDADE PENAL: UM ESTUDO COM PROTAGONISTAS DA REDE DE PROTEÇÃO
}

\author{
REPRESENTACIONES SOCIALES SOBRE REDUCCIÓN DE LA MAYORIDAD \\ PENAL: UM ESTUDIO CON PROTAGONISTAS DE LA RED DE PROTECCIÓN
}

\author{
SOCIAL REPRESENTATIONS ON THE REDUCTION OF CRIMINAL \\ MAJORITY: A STUDY WITH PROTAGONISTS OF THE PROTECTION \\ NETWORK
}

\author{
Adolfo Antonio HICKMANN ${ }^{1}$ \\ Araci ASINELLI-LUZ ${ }^{2}$ \\ Edival Sebastião TEIXEIRA ${ }^{3}$ \\ Girlane Moura HICKMANN ${ }^{4}$
}

RESUMO: O artigo relata investigação que teve por objetivo identificar quais são as representações sociais sobre a redução da maioridade penal evocadas pelos atores sociais que compõem a Rede de Proteção de crianças e adolescentes na região metropolitana de Curitiba. A pesquisa teve 143 participantes, sendo $84 \%$ mulheres e $16 \%$ homens. Os dados foram colhidos mediante a utilização de um protocolo que continha questões de identificação e uma questão de evocação livre cujo termo indutor era Redução da Maioridade Penal. Para o tratamento dos dados obtidos pela evocação livre, utilizou-se o programa computacional EVOC e para o tratamento dos dados obtidos com as demais questões procedeu-se à análise de conteúdo. Os resultados obtidos sugerem que as representações sociais sobre redução da maioridade penal estruturam-se em torno dos elementos Educação, Responsabilidade, Família, Direito e Injustiça. Os sujeitos da pesquisa consideram as propostas de mudança da idade relacionada à maioridade penal como uma injustiça para com a criança e para com o adolescente e que o Estado não está priorizando políticas públicas adequadas para a resolução dos problemas que afetam os jovens brasileiros.

PALAVRAS-CHAVE: Educação. Representações Sociais. Maioridade Penal. Rede de Proteção.

RESUMEN: El artículo relata investigación que tuvo como objetivo identificar cuáles son las representaciones sociales sobre la reducción de la edad penal evocadas por los actores sociales que conforman la red de protección de niños y adolescentes en la región metropolitana de Curitiba. La encuesta tuvo 143 participantes, 84\% mujeres y 16\% hombres. Los datos fueron recolectados mediante el uso de un protocolo que contenía preguntas de identificación y una cuestión de evocación libre cuyo término inductor fue la reducción de la mayoridad penal. Para el tratamiento de los datos obtenidos por la evocación libre, se utilizó el programa computacional EVOC y para el tratamiento de los datos obtenidos con las otras cuestiones se ha procedido el análisis de contenido. Los resultados obtenidos sugieren que las representaciones sociales acerca de la reducción de la edad legal se estructuran en torno a los elementos Educación,

\footnotetext{
${ }^{1}$ Doutorando em Educação pelo PPGE/UFPR. Email: hickmannadolfo@ gmail.com

${ }^{2}$ Doutora em Educação, professora do Programa de Pós-Graduação em Educação, UFPR, Brasil. Vicecoordenadora do NEPS - Núcleo de Estudos de Pedagogia Social NEPS/UFPR. Email: araciasinelli@hotmail.com

${ }^{3}$ Professor Associado da Universidade Tecnológica Federal do Paraná. Docente no Programa de Pósgraduação em Desenvolvimento Regional. Email: edival@utfpr.edu.br

${ }^{4}$ Doutoranda em Educação pelo PPGE/UFPR. Email: girlanehickmann@ gmail.com
} 
Responsabilidad, Derecho de Familia y Injusticia. Los sujetos de la investigación consideran las propuestas de cambios de la edad relacionada con la mayoridad penal como una injusticia para el niño y el adolescente y que el Estado no está dando prioridad a las políticas públicas adecuadas para resolucionar los problemas que afectan a los juvenes brasileños.

PALAVRAS CLAVE: Educación. Representaciones sociales. Mayoridad penal. Red de protección.

ABSTRACT: This article reports a research that aimed to identify which are the social representations about the reduction of penal age evoked by social actors. This actors are part of the Protection Network of children and adolescents in the metropolitan area of Curitiba. The survey had 143 participants, being 84\% of them female and $16 \%$ male. The data were collected using a protocol that contained questions of identification and a question of free recall whose term inducer was Reduction of Criminal Majority. The computer program EVOC was used for the treatment of the data obtained by the free evocation. For other questions it was carried out content analysis. The results obtained suggest that the social representations about reduction of the criminal majority are structured around the elements: Education, Responsibility, Family, Law and Injustice. The subjects of the research consider the proposals of changing of the age related to the criminal majority as an injustice towards the child and also to adolescent and that the State is not prioritizing adequate public policies for the resolution of the problems that affect the young Brazilians.

KEYWORDS: Education. Social Representations, Criminal Majority, Protection Network.

\section{Introdução}

A discussão sobre a redução da maioridade penal no Brasil está inserida no conceito histórico da responsabilidade penal e suas reconfigurações desde suas origens no período colonial brasileiro. Até o Império (1808 a 1830), a responsabilidade penal era regida pelas Ordenações Filipinas, que traziam em si os rigores do Direito Romano. De acordo com tais ordenações, a imputabilidade penal era iniciada aos sete anos de idade. E seguia a norma:

\footnotetext{
Quando o delinquente for menor de dezessete anos cumpridos, posto que o delito mereça morte natural, em nenhum caso lhe será dada, mas ficará em arbítrio do julgador dar-lhe outra menor pena. E não sendo o delito tal, em que caiba pena de morte natural, se guardará a disposição do Direito comum. (PIERANGELLI, 1980, p. 133-134).
}

Segundo o sistema jurídico vigente, a maioridade penal, no Brasil, dá-se aos 18 anos de idade, o que indica a adoção do sistema biológico como parâmetro, independentemente de sua capacidade psíquica. Essa norma encontra-se inscrita em três 
instâncias legais: 1) artigo 27 do Código Penal; 2) artigo 104 do Estatuto da Criança e do Adolescente; 3) artigo 228 da Constituição Federal.

A questão da vulnerabilidade em que se encontram as crianças e adolescentes e a análise dos dados sociais que envolvem essa discussão são importantes na compreensão do processo de vitimização imposto pela violência social e pela inserção desses atores como protagonistas da própria violência. No Brasil, ações históricas têm sido tomadas na busca de soluções repressivas e punitivas. Na linha do tempo, em comum, o uso de drogas, homicídios, assaltos, abandono e negligência, quanto aos nossos jovens, são presentes em qualquer época e sob qualquer regime político.

A promulgação do Estatuto da Criança e do Adolescente, o ECA, Lei $n^{\circ}$ 8.069/1990 (BRASIL, 2011), trouxe regras e princípios relativos à proteção integral e prioridade absoluta, a serem aplicados em benefício das crianças e dos adolescentes. Os princípios do conceito de proteção integral estão sintetizados no artigo $227^{5}$ da Constituição Federal (BRASIL, 1998) e definem crianças e adolescentes como sujeitos de direito, em estágio peculiar de desenvolvimento físico, psicológico e moral, sujeitos à proteção integral.

Com o advento do ECA, o Brasil passou a ter uma das mais avançadas normas, inserida nas diretrizes da legislação especializada em infância e juventude mundial. Em seu artigo $18^{\circ}$, há a recomendação de que "É dever de todos velar pela dignidade da criança e do adolescente, pondo-os a salvo de qualquer tratamento desumano, violento, aterrorizante, vexatório ou constrangedor" (BRASIL, 2011).

O Estatuto tem por objetivo "[...] firmar um sistema de garantia dos direitos da criança e do adolescente de acordo com o paradigma da proteção integral e estabelecer um processo de cidadania, participação e descentralização não presentes nos códigos anteriores.” (PAIXÃO, 2008, p. 23). Nesse viés, a criação dos Conselhos Tutelares constituiu uma conquista inovadora, uma vez que se descentralizou parte da responsabilidade das ações ligadas à infância e à adolescência, cabendo ao âmbito municipal tais tarefas.

${ }^{5}$ Art. 227 - É dever da família, da sociedade e do Estado assegurar à criança, ao adolescente e ao jovem, com absoluta prioridade, o direito à vida, à saúde, à alimentação, à educação, ao lazer, à profissionalização, à cultura, à dignidade, ao respeito, à liberdade e à convivência familiar e comunitária, além de colocá-los a salvo de toda forma de negligência, discriminação, exploração, violência, crueldade e opressão. (BRASIL, 1998). 
No contexto da proposta do presente artigo, entende-se a importância de se conhecer o que pensam os atores sociais partícipes da pesquisa, componentes da Rede de Proteção de Crianças e Adolescentes na Região Metropolitana de Curitiba. Portanto, justifica-se o presente trabalho que descreve as representações sociais da redução da maioridade evocadas por atores sociais que compõem a Rede de Proteção.

\section{A dinâmica da juventude brasileira}

A compreensão das ações repressivas praticadas contra crianças e adolescentes está no olhar que tem se dado ao delito, enquanto um objeto criminológico que estigmatiza os comportamentos juvenis em suas diversas manifestações. Por um lado, a sociedade parece acreditar que estará segura ao encarcerar as crianças e os jovens, garantindo com isso a contenção do medo (LIMA, 2009). Por outro, a problemática da violência na adolescência mostra o fato de que os jovens são protagonistas da violência.

O modo como morrem nossos adolescentes, particularmente nos grandes centros urbanos, aqui e em outros lugares do mundo, é tão significativo e revelador da trama (drama) social quanto o modo como matam. Ambos os aspectos estão inscritos no mesmo ambiente sociocultural que produz, legitima e mantém a violência em seu aspecto mais extremo - a morte. (TRASSI, 2006, p. 215).

Os seres humanos, pelas características de suas próprias naturezas e os ambientes em que vivem, tendem a resguardarem-se e a criar mecanismos de proteção contra a violência. Isso parece, a cada dia, aumentar mais o foco de tensão e de repressão.

O tema 'adolescência-violência' é um ponto crítico, de saturação, condensação de múltiplas determinações, pois revelador das mutações, transformações da cultura, dos padrões de relações entre os humanos, da fragilidade dos vínculos amorosos, do modo de pensar, sentir, agir estar no mundo - dos indivíduos, nesse momento histórico. (TRASSI, 2006, p. 205).

A temática da redução da maioridade penal chama a atenção para a compreensão da ameaça às fronteiras dos direitos humanos. Entre punir e absolver existe também uma reflexão a ser feita quanto ao valor supremo que se deveria dar à vida dos protagonistas envolvidos: 
Sobre esta questão da menoridade há nevoeiros perpétuos [...]. Talvez a mais grave seja o fato de se passar da inimputabilidade para a imputabilidade, sem a admissão de uma zona fronteiriça entre ambas. [...] passa-se do nada para o tudo, da inimputabilidade para a imputabilidade, da absolvição para a condenação, cujo maniqueísmo agride frontalmente as leis da natureza e da vida. Na natureza, nada se dá aos saltos (natura non facit saltus), ou seja, quando terminar a noite não é exatamente naquele momento que começa o dia: há entre ambos, a aurora. (PALOMBA, 2003, p. 509).

Entender a violência no âmbito da juventude implica considerar os padrões de sociabilidade e seus efeitos na esfera pública e privada, suas relações e interconexões com as redes de exploração, as redes de proteção, sociedade, família e escola. "Violência implica a relação de poder e as relações políticas, bem como a cultura e o sistema simbólico de relações sociais". (MEDEIROS, 2006, p. 201).

A dinâmica sociocultural da juventude, seus ideais e sonhos ainda em processo de amadurecimento têm sido objeto de estudos no Brasil na contemporaneidade. A pesquisa "Perfil da juventude brasileira", cuja amostra foi de 3.501 entrevistados, envolvendo homens e mulheres, na faixa etária de 15 a 24 anos, de capitais e regiões metropolitanas, áreas urbanas e rurais, analisou o acesso de jovens a projetos e atividades culturais e/ou esportivas, disponíveis em sua área de convivência. Os dados revelaram que 88\% dos jovens afirmaram nunca terem participado deles e esse número aumenta para 94\% nos meios rurais (BRENNER, DAYRELL; CARRANO, 2005). Embora ofertadas, as oportunidades de acesso não foram efetivas, especialmente quando comparadas as regiões urbana e rural. "A juventude é um coletivo definido por um segmento de idade. Esta coorte etária é simbólica, pois, na maioria das vezes, é usada para segregar um grupo específico e apresentá-lo com problema social" (MEDEIROS, 2006, p. 200).

Observa-se também que a concepção de adolescência do Estatuto da Criança e do Adolescente focaliza o aspecto biológico do desenvolvimento humano: "Considera-se criança, para os efeitos desta Lei, a pessoa até doze anos de idade incompletos, e adolescente aquela entre doze e dezoito anos de idade". (BRASIL, 2011). Completa essa concepção a seguinte definição: "Os direitos de todas as crianças e adolescentes menores de 18 anos foram expressos de tal forma a proteger não só o seu bem-estar, mas também dar-lhes um lugar central como detentores de direitos, proporcionando uma base ética pela sua participação ativa em todos os aspectos de suas vidas. (UNICEF, 2011, p. 12 tradução nossa). O mesmo relatório internacional, mais abaixo afirma que: "Hoje, é amplamente reconhecido que a adolescência é uma fase distinta tanto da primeira 
infância, como da idade adulta: um período que requer especial atenção e proteção". (Id. p. 12 - tradução nossa).

Pode-se dizer que a adolescência é um conceito representacional historicamente construído pelos seres humanos em determinadas culturas e é um estágio biopsicossocial plenamente aceito pela sociedade. Ela constitui uma etapa crucial do processo de crescimento e desenvolvimento humano, cuja marca é a transformação. Quase uma metamorfose, tamanho o impacto sobre o corpo, a mente, o comportamento, as relações humanas, os interesses, a sexualidade e a identidade. Assim, a puberdade, com as mudanças orgânicas que se manifestam no corpo, revela-se como o início da adolescência. Além da mudança do esquema corporal e da percepção do próprio corpo, também o desenvolvimento da identidade pessoal se processa de forma singular nessa fase da vida.

Os processos de mudanças corporais e de socialização do adolescente são desafios que levam a conflitos, denominados por Erikson (1971) conflito entre identidade e difusão de papéis. Na adolescência, a separação progressiva dos pais e a consequente identificação com figuras substitutivas levam à construção de identidades diferentes do meio familiar. Por isso, é comum o adolescente filiar-se a tribos (punks, góticos, emos, skatistas, nerds, patricinhas, mauricinhos, etc.), de acordo com atitudes e comportamentos que compartilha, procurando imitar seus papeis e expressando, de forma simbólica, o que desejaria ser em detrimento do que é.

O que deixa transparecer que há muitos tipos de adolescentes que habitam os espaços urbanos, o que contribui para o fato social de os adolescentes 'ficarem' com os outros, testando-se e assumindo, por vezes, identidades circunstanciais até conquistarem o processo de individualização. (MENDES, 2012, p. 21).

Corroborando essas ideias, existem características indicativas de aspectos da adolescência, como: busca de si mesmo e da identidade; tendência grupal e necessidade de fantasiar, entre outros. (ABERASTURY; KNOBEL, 1989). Além disso, o período da adolescência marca também a rebeldia do adolescente em busca de sua autonomia (CALLIGARIS, 2000). Nesse aspecto, crê-se que o contraponto externado pelos jovens em contestar e polemizar as instruções dos adultos pode ser mediado eficazmente por vínculos afetivos significativos, que poderão exercer importante controle sobre essas 
condutas. Verifica-se o importante potencial de contrapartida das ações da família, da escola e da sociedade (microssistemas e mesossistemas ${ }^{6}$ ) nas mediações de conflitos.

A Teoria Bioecológica do Desenvolvimento Humano considera as relações interpessoais e o ambiente, ambos em constante mudança. Propõe que o ambiente natural é formado em contextos de interações ou sistemas influenciados pelas mudanças que ocorrem no indivíduo através do tempo (BRONFENBRENNER, 2011).

Para a juventude, o locus principal de sociabilidade é o bairro e a vizinhança. Nesse sentido, uma pesquisa sobre a juventude evidenciou que $47 \%$ dos jovens apontam o bairro e a vizinhança como o principal espaço de fazer amigos, seguido pela escola, com $40 \%$. No entanto, se considerada a adolescência mediana (15 a 17 anos), “[...] a escola é o lugar privilegiado de fazer amigos (54\%), mais do que o bairro. Já para a faixa etária de 21 a 24 anos, espaços como o trabalho tornam-se mais significativos do que a escola no estabelecimento de laços de amizade, ainda que não a supere”. (BRENNER, DAYRELL; CARRANO, 2005, p. 208). Verifica-se a importância da inserção dos indivíduos na estrutura social em que vivem, alicerçados pelas ações do poder público, que deve criar condições favoráveis e espaços de circulação dos jovens pela cidade (BRENNER, DAYRELL; CARRANO, 2005).

Essa rápida contextualização do ser criança e adolescente no contexto contemporâneo permite visualizar a complexidade das relações interpessoais que vão ocorrendo no decorrer dessa fase do desenvolvimento humano. Contribui para essas constatações a declaração de que para “[...] as novas gerações, o mundo parece cada vez mais pré-definido, fechado e ocupado. Isto possivelmente incide no processo de socialização com determinadas características, quando se é jovem”. (BAÑO, 2000, p. 172).

Diante dessas considerações, a pesquisa considerou a importância mediadora exercida pelos atores das Redes de Proteção localizadas na Região Metropolitana de Curitiba, reforçada pelas recomendações de especialistas do direito da criança e do adolescente, conforme se verifica abaixo:

Em outro ângulo, é necessário ampliar cada vez mais a participação da sociedade civil nas instâncias democráticas dos Conselhos Tutelares, a quem incumbe fiscalizar o adequado funcionamento de todo o sistema de atendimento à infância e juventude (podendo inclusive requisitar serviços públicos para viabilizar a execução das medidas que aplica) e

${ }^{6}$ Inseridos na Teoria Bioecológica do Desenvolvimento Humano, os primeiros, microssistemas, correspondem aos ambientes imediatos de interação da pessoa com o mundo (família, escola, grupos de amizade, entre outros); os segundos, mesossistemas, são as interações que ocorrem entre os diversos ambientes imediatos dos seres humanos. (BRONFENBRENNER, 2011). 
dos Conselhos dos Direitos da Criança e do Adolescente. (DIGIÁCOMO, 2010, p. 2).

Investigar e conhecer o que pensam esses atores sobre a redução da maioridade penal é a base para o aprofundamento de pesquisas no campo da Psicologia Social, enquanto engajada com as demandas sociais de jovens brasileiros. As ferramentas de pesquisa oferecidas pela teoria das Representações Sociais apresentam subsídios teóricopráticos para o entendimento dessas questões e poderão nortear ações futuras embasadas em teoria consistente.

\section{A Teoria das Representações Sociais}

A teoria das representações sociais tem sido utilizada em estudos nessa área, tal como se observa nos trabalhos de Espíndula et al. (2006) e de Corte Real e Conceição (2013). No primeiro estudo os pesquisadores analisaram as representações de adolescentes em conflito com a lei na imprensa escrita do Estado do Espírito Santo. Já no segundo, os autores investigaram as representações sociais sobre redução da maioridade penal em um grupo de parlamentares brasileiros.

Nas duas pesquisas, as conclusões remetem a que as representações sociais sobre jovens em conflito com a lei, ou sobre a redução da maioridade penal, estão fortemente baseadas nos ditames do antigo Código de Menores e em total desacordo, ou mesmo ignorância, para com a “doutrina da proteção integral presente em nosso Estatuto da Criança e do Adolescente". (CORTE REAL; CONCEIÇÃO, 2013, p. 669).

Na pesquisa social, a expressão "representações sociais" refere-se a um fenômeno e a um método, isto é, a um objeto e a uma teoria que o explica e que orienta o seu estudo. Enquanto objeto, as representações sociais têm a ver com formas de conhecimento elaborados socialmente e partilhados, que permitem a construção de uma realidade comum a determinado grupo social.

Igualmente designada como saber do senso comum ou ainda saber ingênuo, natural, esta forma de conhecimento é diferenciada, entre outras, do conhecimento científico. Entretanto, é tida como um objeto de estudo tão legítimo quanto este, devido à sua importância na vida social e à elucidação possibilitadora dos processos cognitivos e das interações sociais. (JODELET, 2001, p. 22). 
Portanto, as representações sociais em si mesmas não são conhecimentos de tipo científico, ainda que determinada representação social possa ter origem num conhecimento científico, como é o caso da representação social de psicanálise investigada por Moscovici (2012). Então, as representações sociais enquanto fenômeno, isto é, como objeto, consistem em um conjunto de valores, ideias e práticas que possibilitam às pessoas orientarem-se em seu mundo material e social, bem como se comunicarem, na medida em que fornece aos membros de determinada comunidade um conjunto de códigos que permite classificar e nomear os vários aspectos da realidade individual e coletiva (MOSCOVICI, 2003).

Já enquanto método, a teoria considera "a diversidade dos indivíduos, atitudes e fenômenos, em toda sua estranheza e imprevisibilidade", tendo por objetivo "descobrir como os indivíduos e grupos podem construir um mundo estável, previsível, a partir de tal diversidade" (MOSCOVICI, 2003, p. 79). As representações sociais são geradas por dois processos cognitivos: a ancoragem e a objetivação. Por meio desses processos, os indivíduos inserem em seus quadros de referência o "novo", comparando-o e interpretando-o relativamente ao já familiar, o que permite, por sua vez, reproduzi-lo e controlá-lo (Ibid., 2003).

A ancoragem é o processo por meio do qual o indivíduo suporta e transforma o desconhecido, reduzindo-o a categorias e imagens relacionadas a coisas que lhes são familiares. Isto é, a ancoragem "transforma algo perturbador, que nos intriga, em nosso sistema de categorias e o compara com um paradigma de uma categoria que nós pensamos ser apropriada". (MOSCOVICI, 2003, p. 61). Por essa razão, o autor em questão afirma que sua teoria não concebe a existência de um pensamento ou uma percepção que não possuam ancoragem, porque os sistemas de classificação e nomeação não são simplesmente meios para rotular ou graduar pessoas ou objetos.

A ancoragem tem a ver, então, com a assimilação de imagens, ideias e pensamentos novos, a cognições anteriores, propiciando, dessa forma, o surgimento de novas representações sociais. Por meio desse processo os acontecimentos são incorporados e reinterpretados mediante três condições: a primeira condição é a atribuição de um sentido ao objeto novo que se relacione com algum sentido já estabelecido, já portador de um significado; a segunda condição tem a ver com a instrumentalização do saber, mediante a qual o sujeito interpreta o conhecimento novo dando-lhe uma nova forma, traduzindoo e incorporando-o ao seu universo socialmente vivido; finalmente, a terceira condição 
consiste no enraizamento, isto é, uma espécie de organização estrutural do objeto novo ao sistema de pensamento do sujeito (MOSCOVICI, 2003).

A objetivação, por sua vez, torna concreto algo abstrato, como a transformação de uma ideia, um pensamento, em uma ação, em um ato de comportamento. Em outras palavras, o que é uma cognição, pelo processo da objetivação, transforma-se em algo tangível; de uma cognição a um ato manifesto. É, pois, pelo construto da objetivação que se explica o fato de um ente imaginário tornar-se um ente "quase tangível". (MOSCOVICI, 2003).

Portanto, a objetivação é o processo por meio do qual se une o não familiar com a realidade, tornando, dessa forma, esse não familiar em realidade. Assim, "percebida primeiramente como um universo puramente intelectual e remoto, a objetivação aparece, então, diante de nossos olhos, física e acessível. [...] objetivar é descobrir a qualidade icônica de uma ideia; é reproduzir um conceito em uma imagem" (MOSCOVICI, 2003, p. 72).

Autores como Sá (1998) e Almeida (2009) consideram a teoria das representações sociais como uma grande teoria no sentido em que sua finalidade é a de propor conceitos de base para a identificação e análise de diferentes dinâmicas sociais. Essa grande teoria de que falam Sá e Almeida desdobra-se em correntes complementares, não incompatíveis entre si pelo fato de provirem da mesma matriz (SÁ, 1998). As principais correntes teóricas que se desenvolveram a partir da grande teoria são: a abordagem culturalista; a abordagem societal; a abordagem estrutural.

$\mathrm{Na}$ abordagem estrutural, a qual orienta o estudo ora relatado, considera-se que toda representação social organiza-se e estrutura-se em torno de um núcleo central. De acordo com Franco (2004), toda objetivação que se cristaliza passa a constituir o núcleo de determinada representação, o qual é composto por um ou vários elementos cuja finalidade é, ao mesmo tempo, dar uma significação e uma espécie de organização à representação. Assim, é a presença de determinados elementos centrais que asseguram a permanência de uma representação (SÁ, 1996).

É pela identificação desse núcleo que se infere a existência de consensos relativamente compartilhados acerca de algum objeto. Por essa razão, entende-se que o núcleo central repercute a memória coletiva, o que implica admitir que sua formação seja marcada pelas condições históricas inerentes ao contexto do grupo social que o manifesta (SÁ, 1996; FRANCO, 2004; CROMACK, BURSZTYN; TURA, 2009). 
O núcleo central organiza-se como uma estrutura hierarquizada, que se determina pela natureza do objeto e pelo sistema de valores e normas sociais que constituem o contexto ideológico do grupo. Este núcleo é formado por um ou mais elementos que dão o significado à representação, de modo que se constitui como seu elemento essencial.

De acordo com Sá (1996; 1998), em torno dos atributos centrais de uma representação orbitam um conjunto de elementos periféricos passíveis de captação e compreensão. O núcleo central confere uma base relativamente estável à representação, de modo que se caracteriza por ser um tanto resistente a mudança. Por isso, "assegura a continuidade e a permanência de uma representação por tempos mais ou menos longos" (POLLI et al., 2009), a despeito do contexto imediato no qual a representação é posta em evidência.

Cromack, Bursztyn e Tura (2009, p. 628), afirmam que o sistema periférico "promove a interface entre a realidade concreta e o núcleo central, atualizando-o e contextualizando-o constantemente, daí resultando sua mobilidade e flexibilidade, permitindo a expressão individualizada e tornando possível que a representação social se ancore na realidade do momento". Por isso o sistema periférico é mais maleável, suscetível à mudança e consegue integrar experiências particulares, heterogeneidade e idiossincrasias.

\section{Metodologia}

Os participantes da pesquisa compareceram à audiência pública intitulada Garantia da Proteção Integral à Criança e ao Adolescente - 23 anos da lei 8.069/90 e a questão da Maioridade Penal, ocorrida em setembro de 2013. O evento foi promovido em parceria entre o NEPS - Núcleo de Estudos em Pedagogia Social - Setor de Educação da Universidade Federal do Paraná - UFPR e os Conselhos Tutelares de Curitiba. Todos aceitaram voluntariamente participar da pesquisa e, para isso, assinaram um termo de consentimento livre e esclarecido.

Os dados foram colhidos mediante a utilização de um protocolo que continha questões de identificação e uma questão de evocação livre cujo termo indutor era Redução da Maioridade Penal.

Aos participantes foi solicitado que escrevem em formulário apropriado as quatro primeiras palavras que lhes viessem à mente mediante o termo indutor mencionado. 
Posteriormente deveriam justificar suas evocações, escolher as que consideravam mais importantes e explicar o porquê dessas escolhas.

Os dados obtidos com as questões de evocação livre foram tratados mediante a utilização do software EVOC. Para tanto foram desprezadas as palavras evocadas menos do que três vezes e a frequência intermediária escolhida foi igual a 10. Já os dados obtidos pelas questões dissertativas - aquelas em que se pedia aos participantes para justificarem suas respostas - foram analisados visando à busca dos significados e dos sentidos atribuídos pelos respondentes aos elementos que evocaram.

O programa EVOC separa os elementos evocados em quatro conjuntos. $\mathrm{O}$ primeiro conjunto é composto pelos elementos mais relevantes, isto é, os que são mais evocados que os demais e que são mencionados em primeiro lugar pelos sujeitos. Ou seja, os mais evocados e mais prontamente evocados. Tais elementos seriam os mais suscetíveis de pertencer ao núcleo central da representação (ALVES-MAZZOTI, 2007; MACHADO; ANICETO, 2010).

O segundo conjunto é composto pelos elementos da periferia próxima, sendo estes dentre os mais evocados, porém dentre os menos prontamente evocados. Isto é, elementos que aparecem bastante nas respostas dos participantes, mas que surgem mais tardiamente que os demais.

Por sua vez, o terceiro conjunto de elementos é formado por aqueles dentre os que aparecem em menor número nas respostas, mas que, por outro lado, surgem mais repentinamente. Dito de outro modo, os elementos menos evocados, porém, mais prontamente evocados. Tais elementos, para Alves-Mazzotti (2007) estão dentre os de menor precisão de interpretação.

Por fim, no quarto conjunto encontram-se os elementos menos evocados e menos prontamente evocados. Isto é, os elementos menos frequentes e de aparição mais tardia nas respostas dos participantes da pesquisa. Esses são os que compõem a periferia do núcleo central (ALVES-MAZZOTI, 2007; MACHADO; ANICETO, 2010).

Para inferências sobre as representações sociais em análise, os resultados obtidos com o programa computacional EVOC foram cotejados com os dados obtidos pela análise das respostas dadas às questões dissertativas. Mediante esse procedimento foi possível identificar tanto a frequência dos elementos evocados, sua aparição mais precoce ou mais tardia nas repostas dos participantes e, sobretudo, os significados e sentidos atribuídos às evocações. 


\section{Resultados e discussão}

Os participantes da pesquisa eram educadores sociais, professores, advogados, psicólogos, conselheiros tutelares, jornalistas, gestores públicos, políticos, entre outros atores da sociedade civil organizada, num total de 257 pessoas presentes na audiência pública, das quais 143 concordaram em responder às perguntas propostas pela pesquisa. Dentre os 143 participantes da pesquisa, 84\% eram mulheres e 16\% homens. Quanto à escolaridade, $92 \%$ dos deles tinha formação de nível superior, sendo alguns com titulação de mestrado ou doutorado.

Ante o termo indutor Redução da Maioridade Penal os participantes fizeram 585 evocações, empregando 223 palavras distintas. Excluindo-se da análise todas as palavras que foram evocadas menos de três vezes, restaram 55 vocábulos, os quais foram mencionados 381 vezes $(61,13 \%)$ do total das evocações. A ordem média de evocação encontrada foi igual a 2,49. Neste texto, esses vocábulos serão doravante referidos como elementos. O quadro a seguir apresenta os resultados obtidos, excluindo-se, contudo, os elementos cuja frequência foi inferior a cinco.

QUADRO 1 - Distribuição dos elementos evocados conforme a frequência intermediária (FI), a frequência de evocação $(f)$, e a ordem média de evocação $(O m e)$.

\begin{tabular}{|c|l|c|c|l|c|c|}
\hline FI & Elementos & $\boldsymbol{F}$ & $\begin{array}{c}\text { Ome } \\
<\mathbf{2 , 4 9}\end{array}$ & \multicolumn{1}{|c|}{ Elementos } & $\boldsymbol{f}$ & $\begin{array}{c}\text { Ome } \\
\mathbf{>}\end{array}$ \\
\hline \multirow{5}{*}{$>10$} & Educação & 39 & 2,47 & Políticas públicas & 26 & 2,80 \\
& Responsabilidade & 17 & 1,70 & Desrespeito & 16 & 2,75 \\
& Família & 17 & 2,05 & Violência & 13 & 3,00 \\
& Direito & 16 & 2,27 & & & \\
& Injustiça & 16 & 2,45 & & & \\
\hline \multirow{5}{*}{$\leq 10$} & Prevenção & 10 & 1,90 & Violação & 9 & 2,55 \\
& Proteção & 9 & 2,44 & Erro & 8 & 2,50 \\
& ECA & 7 & 1,85 & Oportunidade & 8 & 2,75 \\
& Absurdo & 7 & 2,14 & Sociedade & 6 & 2,66 \\
& Justiça & 7 & 2,42 & Responsabilização & 6 & 3,33 \\
& Desconhecimento & 6 & 1,80 & Abandono & 5 & 2,60 \\
& Penalização & 6 & 2,33 & Retrocesso & 5 & 2,60 \\
& Contrário & 5 & 1,60 & & & \\
\hline
\end{tabular}

Fonte: Elaboração própria a partir de dados coletados e organizados pelos autores. 
Como se pode observar pelos resultados alocados no quadrante superior esquerdo (Núcleo central), os elementos Educação, Responsabilidade, Família, Direito e Injustiça foram os mais evocados e mais prontamente evocados, tornando-se, dessa maneira, os mais suscetíveis de pertencer ao núcleo central das representações sociais sobre redução da maioridade penal dos sujeitos da pesquisa.

Por sua vez, na periferia próxima, quadrante superior direito, estão os elementos Políticas públicas, Desrespeito e Violência, os quais, embora não estejam dentre os mais prontamente evocados, são importantes na estrutura das representações sociais em análise, como se demonstrará a seguir.

Com efeito, ao serem cotejados os elementos mais suscetíveis de pertencer ao núcleo central e os elementos da periferia próxima com os resultados obtidos pela análise das questões dissertativas, pôde-se identificar que para os participantes da pesquisa a redução da maioridade penal consistirá, caso seja mesmo tornada lei, numa injustiça que se cometerá para com os jovens em geral, e para com os em conflito com a lei, mais especificamente, tendo em vista que o problema é menos uma questão de impunidade ou de violência do que uma questão de direitos elementares do cidadão que não têm sido adequadamente atendidos pelo Estado.

O elemento Educação, cuja frequência de evocação é disparadamente superior a todas as demais frequências, aparece quase sempre associado com elementos que denotam a ausência ou a ineficiência do Estado em relação a direitos básicos do cidadão e os elementos Família e Responsabilidade, nas respostas dissertativas, sugerem que a própria educação escolar, enquanto responsabilidade do Estado e das famílias é um dos elementos mais importantes para os sujeitos da pesquisa em relação aos problemas dos jovens com conflito com a lei, e que parecem ser frequentemente negados.

Os demais elementos das periferias da representação social em análise, tais como Absurdo, Justiça, Desconhecimento, Penalização, Violação, Erro, Responsabilização, Abandono e Retrocesso, quadrante inferior esquerdo, também possibilitam a observação de que os sujeitos da pesquisa apontam enfaticamente para a violação de direitos de que têm sido vítimas expressiva parcela da juventude brasileira. Assim, apesar dos muitos sentidos atribuídos pelos participantes ao termo indutor proposto, a redução da maioridade penal consistirá, para os mesmos, antes em mais uma violação do que uma resposta à sociedade ante os problemas dos jovens em conflito com a lei.

Os resultados obtidos contrastam com os expostos por Espíndula et al. (2006) e Corte Real e Conceição (2013), autores que apontam para a ignorância de seus sujeitos da 
pesquisa em relação às diretrizes do Estatuto da Criança e do Adolescente, cujo foco central é a doutrina da proteção integral. Acrescente-se a isso o proposto por John Rawls, que apresentou a Teoria da Justiça Social (1971), cujo epicentro é a justiça distributiva e estabelece a organização básica de uma sociedade plenamente democrática para contribuir com a eliminação progressiva das violências estruturais que se encontram na base da configuração socioeconômica mundial e que representa os embriões dos desequilíbrios contemporâneos: pobreza, exclusão, marginação, etc. (ENTRENA JIMÉNEZ; MARTÍNEZ-RODRÍGUEZ, 2013).

Paralelo a isso, uma pesquisa realizada junto a assistentes de desenvolvimento social que cuidam de adolescentes em conflito com a lei que cumprem medidas socioeducativas em regime de internação na Região Metropolitana do Recife, objetivou verificar as representações sociais desses atores a respeito dos adolescentes em conflito com a lei. A pesquisa apresentou os seguintes achados centrais: a delinquência dos adolescentes parece estar ligada ao fato da falta de cuidados e à ausência de limites dos pais e à fase de transição adolescente. Sugere-se uma transformação cultural no modo como a sociedade contemporânea concebe o adolescente, em especial o infrator (ESPÍNDULA; SANTOS, 2004).

Atualmente, há no Brasil três Propostas de Emenda à Constituição (PEC) para votação na Comissão de Constituição, Justiça e Cidadania (CCJ) que determinam sobre a redução da maioridade penal no Brasil: PEC 74/2011, PEC 83/2011 e PEC 33/2012. Uma delas legisla sobre a inimputabilidade de atos de pessoas de até os 16 anos, e as outras duas são mais flexíveis, cujas punições dependerão da gravidade do delito. (MARTINS, 2013).

Pesquisas de opinião veiculadas pela mídia indicam que a população brasileira, em sua maioria (92,7\%), está a favor da diminuição da maioridade penal (DOURADO, 2013). No país, existe um debate sobre essa problemática restrito aos âmbitos jurídicos e políticos. Contudo, considerando-se essa questão, nos debates, o fenômeno-crime tem prevalecido de tal forma sobre o aspecto da violência contra direitos dos jovens que as correntes que prendem a sociedade brasileira em grilhões fabricam uma cultura perenal, donde a sociedade segregadora estigmatiza e produz uma espécie de economia de exclusão que parece conduzir ao "etiquetamento e à morte" (LIMA, 2009, p. 23).

No momento em que se analisa e se reflete sobre o posicionamento dos agentes da rede de proteção sobre a discussão em pauta, a Câmara Federal dos Deputados, em uma ação estratégica, um dia depois de ser votada e não aprovada, reapresentou para votação em plenário, no dia 02 de julho de 2015, a proposta de diminuição da maioridade penal 
de 18 para 16 anos em casos de crimes hediondos. Isso provocou indignação e inúmeros pedidos de impedimento e de inconstitucionalidade por parte de instituições judiciárias, dos Direitos Humanos, da Ordem dos Advogados do Brasil, de grupos científicos, religiosos, sociais, educacionais e voltados para a proteção da criança e do adolescente.

Em que pesem as manifestações de estudiosos do fenômeno das violências, do desenvolvimento humano, da juventude, que indicam o equívoco da sociedade e parte de seus representantes políticos em inferir relação entre a diminuição da maioridade penal e a diminuição da violência praticada por adolescentes, argumentos fundamentados em estudos e pesquisas não têm sido devidamente acolhidos pelos legisladores. Assim, o clamor das multidões, acuadas pelo medo e pela desinformação, frente ao aumento dos casos de violência e a glamourização pela mídia dos casos em que adolescentes são os protagonistas, é forte estímulo para a tomada de decisão inconsequente no que tange a lei de tamanha complexidade e impacto na vida de adolescentes vulneráveis aos conflitos com a justiça.

Dessa forma, conhecer as representações sociais dos profissionais diretamente atuantes nas redes de proteção à infância e adolescência, seus argumentos e pressupostos, auxiliam os debates ainda necessários e os encaminhamentos para as políticas públicas atuais e futuras em prol da juventude e da sociedade como um todo.

\section{Considerações Finais}

Face o exposto, pode-se afirmar que as representações sociais identificadas evidenciam o reconhecimento pelos participantes da pesquisa que a discussão da redução da maioridade penal decorre da ausência de políticas de educação, do desconhecimento do legislativo sobre o fenômeno da adolescência e juventude, bem como da responsabilidade familiar e social no cumprimento dos direitos da criança e do adolescente, caracterizando-se como injustiça a responsabilidade penal do adolescente, tendo em vista a violação histórica de seus direitos.

A pesquisa ora relatada demonstrou que, para os participantes da mesma, o Estado brasileiro, antes de tomar decisões precipitadas e equivocadas que impactam o futuro das crianças e adolescentes, necessita conhecer sobre a problemática que afeta os jovens brasileiros. Dessa forma qualifica-se a promover medidas protetivas eficazes, 
possibilitando a esses atores, crianças e adolescentes, voz e vez de protagonistas; em outras palavras, possibilitando a vivência plena de seus direitos.

Através de suas histórias e identidades, os jovens, cidadãos de direitos, terão a oportunidade real de viver seus sonhos e construir seus projetos de vida resilientes, com autonomia, de forma emancipada e plena do gozo da liberdade de ser criança e adolescente, se forem lhes facultado o pleno acesso aos seus direitos fundamentais, em especial à educação, à família cuidadora, ao esporte, ao lazer e ao trabalho aprendiz.

Por fim, os resultados sugerem a necessidade do envolvimento da sociedade civil organizada, da efetividade das políticas públicas voltadas à infância e à adolescência, do fortalecimento das redes protetivas e do aprofundamento de estudos na busca da resolução dos problemas que envolvem a vitimização de crianças e adolescentes enquanto política pública de Estado.

\section{Referências}

ABERASTURY, Arminda; KNOBEL, Mauricio. Adolescência normal: um enfoque psicanalítico. Porto Alegre: Artes Médicas, 1989.

ALMEIDA, Ana Maria Oliveira. Abordagem societal das representações sociais. Sociedade e Estado. Brasília, v. 24, nº 3, p. 713-737, set./dez. 2009.

ALVES-MAZZOTTI, Alda Judith. Representações da identidade docente: uma contribuição para a formulação de políticas. Ensaio: aval. pol. públ. Educ., Rio de Janeiro, v. 15, n. 57, p. 579-594, out./dez. 2007.

BAÑO, Rodrigo. Debates: Desafios da ecologia e da juventude para o novo século. In: KRISCHKE, P. (Org.). Ecologia, Juventude, e Cultura Política. Florianópolis: EDUFSC, 2000. 189 p. 171-188.

BRASIL. Constituição da República Federativa do Brasil. Brasília: Senado Federal, 1998.

BRASIL. Estatuto da criança e do adolescente: lei n. 8.069, de 13 de julho de 1990, e legislação correlata. 8 ed. Brasília: Câmara dos Deputados, 2011.

BRENNER, Ana Karina; DAYRELL, Juarez; CARRANO, Paulo. Culturas do lazer e do tempo livre dos jovens brasileiros. In: ABRAMO, Helena Wendel; BRANCO, Pedro Paulo Martoni (orgs.). Retrato da juventude brasileira: análise de uma pesquisa nacional. São Paulo: Instituto Cidadania/Editora Fundação Perseu Abramo, 2005. p. 175214. 
BRONFENBRENNER, Urie. Bioecologia do desenvolvimento humano: tornando os seres humanos mais humanos. Porto Alegre: Artmed, 2011.

CALLIGARIS, Contardo. A adolescência. São Paulo: Publifolha, 2000.

CORTE REAL, Fabíola Geoffroy Veiga; CONCEICAO, Maria Inês Gandolfo. Representações sociais de parlamentares brasileiros sobre a redução da maioridade penal. Psicol. cienc. prof. [online]. 2013, vol.33, n.3, p. 656-671.

CROMACK, Luiza Maria Figueira; BURSZTYN, Ivani; TURA, Luiz Fernando Rangel. O olhar do adolescente sobre saúde: um estudo de representações sociais. Ciênc. saúde coletiva, vol.14 n. 2, Rio de Janeiro, mar./abr. 2009.

DIGIÁCOMO, Murillo José; DIGIÁCOMO, Ildeara de Amorim. Estatuto da criança e do adolescente anotado e interpretado. Ministério Público do Estado do Paraná. Centro de Apoio Operacional das Promotorias da Criança e do Adolescente: Curitiba, 2010. 487 p.

DOURADO, Kamila. Mais de $90 \%$ da população aprova a redução da maioridade penal. In: R7. Brasília, 11 jun. 2013. Disponível em: <http://noticias.r7.com/brasil/mais-de-90da-populacao-aprova-a-reducao-da-maioridade-penal-11062013>. Acesso em: 24 jan. 2014.

ENTRENA JIMÉNEZ, Socorro; MARTÍNEZ-RODRÍGUEZ, Francisco Miguel. Educación y cambio social: del capitalismo neoliberal a la economía del bien común. In: LÓPEZ, Susana Torío et al. (Coord.). La crisis social y el estado del bienestar: las respuestas de la Pedagogía Social. Oviedo: Universidad de Oviedo, Servicio de Publicaciones, 2013. p. 72-77.

ERIKSON, Erik Homburger. Infância e Sociedade. 2 ed. Rio de Janeiro: Zahar Editores, 1971. $404 \mathrm{p}$.

ESPÍNDULA, Daniel Henrique Pereira et al. "Perigoso e violento": representações sociais de adolescentes em conflito com a lei em material jornalístico. Psic, São Paulo, v. 7, n. 2, p. 11-20, jul./dez. $2006 . \quad$ Disponível em: <http://pepsic.bvsalud.org/scielo.php?script=sci_arttext\&pid=S167673142006000200003\&lng=pt\&nrm=iso>. Acesso em: 17 set. 2014.

ESPÍNDULA, Daniel Henrique Pereira; SANTOS, Maria de Fátima de Souza. Representações sobre a adolescência a partir da ótica dos educadores sociais de adolescentes em conflito com a lei. Psicol. estud., Maringá, v. 9, n. 3, p. 357-367, set./dez. $2004 . \quad$ Disponível em: <http://www.scielo.br/scielo.php?script=sci_arttext\&pid=S1413$73722004000300004 \& \operatorname{lng}=$ en\&nrm=iso>. Acesso em: 17 set. 2014.

FRANCO, Maria Laura Barbosa Puglisi. Representações sociais, ideologia e desenvolvimento da consciência. Cadernos de Pesquisa, v. 34, n. 121, p. 169-186, jan./abr. 2004. 
JODELET, Denise. Representações Sociais: um domínio em expansão. In: JODELET, D. (Org.). As representações sociais. Rio de Janeiro: UERJ, 2001, p. 17-44.

LIMA, Cezar Bueno de. Jovens em conflito com a lei: liberdade assistida e vidas interrompidas. Londrina: EDUEL, 2009.

MACHADO, Laêda Bezerra; ANICETO, Rosimere de Almeida. Núcleo central e periferia das representações sociais de ciclos de aprendizagem entre professores. Ensaio: aval. pol. públ. Educ., Rio de Janeiro, v. 18, n. 67, p. 345-364, abr./jun. 2010.

MARTINS, Carolina. Senado adia debate sobre projetos que tratam da redução da maioridade penal. In: R7. Brasília, 12 nov. 2013. Disponível em: $<$ http://noticias.r7.com/brasil/senado-adia-debate-sobre-projetos-que-tratam-dareducao-da-maioridade-penal-12112013>. Acesso em: 24 jan. 2014.

MEDEIROS, Regina de Paula. Jovens, violência e drogas no contexto urbano. In: CIRINO, Oscar Antônio de Almeida; MEDEIROS, Regina de Paula (Orgs.). Álcool e outras drogas: escolhas, impasses e saídas possíveis. Belo Horizonte: Autêntica, 2006. p. 199-208.

MOSCOVICI, Serge. Representações sociais: investigações em psicologia social. 4 ed. Petrópolis: Vozes, 2003.

MOSCOVICI, Serge. A psicanálise, sua imagem e seu público. Petrópolis: Vozes, 2012.

MENDES, Tania Maria Scuro. Da adolescência à envelhecência: convivência entre as gerações na atualidade. Porto Alegre: Mediação, 2012.

PAIXÃO, Divaneide Lira Lima. Direitos humanos e adolescência no contexto de uma sociedade violenta: um estudo de representações sociais. Tese (Doutorado em Psicologia Social, do Trabalho e das Organizações) - Instituto de Psicologia da Universidade de Brasília. Brasília: UNB, 2008. Disponível em: <http://hdl.handle.net/10482/1748> Acesso em: 29 set. 2014.

PIERANGELI, José Henrique. Códigos penais do Brasil: evolução histórica. Bauru, São Paulo: Javoli, 1980.

POLLI, Gislei Mocelin.; KUHNEN, Ariane; AZEVEDO, Eliza Gonçalves; FANTIN, Jamile \& SILVA, Roberta Ferreira Gasparino. Representações socais da água em Santa Catarina. Psicologia em Estudo, Maringá, v. 14, n. 3, p.529-536, jul./set. 2009.

SÁ, Celso Pereira. Núcleo Central das representações sociais. Petrópolis: Vozes, 1996.

SÁ, Celso Pereira. A construção do objeto de pesquisa em representações sociais. Rio de Janeiro: EDUERJ, 1998.

TRASSI, Maria de Lourdes. Adolescência - violência: desperdícios de vidas. São Paulo: Cortez, 2006. 
UNICEF. The state of the world's children 2011: adolescence: an age of opportunity. UNICEF: New York, 2011.

\section{Como citar este artigo:}

HICKMANN, Adolfo Antonio et al. Representações sociais sobre redução da maioridade penal: um estudo com protagonistas da rede de proteção. Revista Ibero-Americana de Estudos em Educação, Araraquara, v.12, n.1, p. 70-89, 2017. Disponível em: <http://dx.doi.org/10.21723/riaee.v12.n1.7842>. E-ISSN: 1982-5587.

Data de submissão: jul/2015

Aprovação final: jan/2017 